\title{
Electronic cigarettes: it is urgent to promote them to save lives
}

\author{
Antoine Flahault $\cdot$ Jean-François Etter
}

Received: 1 August 2014/Accepted: 11 August 2014/Published online: 7 September 2014

(C) Swiss School of Public Health 2014

Electronic cigarettes (ecigs) were invented in 2004 in China and emerged in 2006 in the USA and Europe. Ecigs were initially manufactured mostly in China, but they are now also produced in other Asian countries, the USA and Europe. Tobacco companies entered this competitive market only recently, initially by purchasing existing brands (e.g., Blu, Green Smoke, Nicolite, E-Lite). In terms of public health, the production, use, and promotion of ecigs are the subject of heated controversies.

Cigarettes kill 6 million people each year globally (WHO 2104). Preventing tobacco smoking is therefore at the top of the public and global health agendas, and has led to an international treaty under the auspices of WHO, the Framework Convention for Tobacco Control (Shibuya et al. 2003). Governments have implemented several interventions aimed at reducing smoking, including tax increases, smoking bans in public and working areas, and media campaigns. Major successes have been reported in many, but not all countries, allowing smoking prevalence to drop dramatically from, e.g., $80 \%$ in males in the UK in the 1950 s to $22 \%$ nowadays (ASH 2014). However, all these "classical" interventions are currently facing their limits, since smoking prevalence is stalling in many

This Commentary is one of three contributions in issue 5 (2014) on electronic cigarettes. The other contributions are available at doi:10.1007/s00038-014-0589-z, 10.1007/s00038-014-0598-y.

A. Flahault $(\bowtie) \cdot$ J.-F. Etter

Institute of Global Health, Faculty of Medecine, University

of Geneva, Geneva, Switzerland

e-mail: antoine.flahault@unige.ch

A. Flahault

Centre Virchow-Villermé, Université Sorbonne Paris Cité,

Paris, France countries, and is increasing in many Asian countries, in particular among women. Sweden ranks first in OECD countries with regards to its low prevalence of smoking in males. It represents an interesting model, since its male population has been using for decades smokeless tobacco products named snus. Swedish males exhibit the lowest rates of lung cancer and oral cancer mortality, two sites of cancers with high attributable fractions to tobacco smoking. There is a high proportion of snus users in Swedish males $(26 \%)$, and Sweden maintains a high level of tobacco use in its male population when the $19 \%$ of smokers are included (Norberg et al. 2011). However, snus allows for a relatively low smoking prevalence, and high health benefits. The high level of consumption of smokeless tobacco in Sweden is explained by cultural habits, tradition and a strong marketing, rather than by public health efforts.

Snus is prohibited in the EU, except in Sweden, although it is a harm reduction strategy which could be sensibly considered. Snus represents a natural experiment in Sweden which tends to demonstrate that smoke kills, not nicotine, and that smokeless tobacco is much less dangerous than cigarettes. We may reasonably assume that a switch from smoking to smokeless alternatives and to ecigs and other nicotine vaporizers can be a useful harm reduction approach, in addition to the existing successful strategies implemented to fight smoking tobacco.

Those who oppose ecigs see them as a strategy from the tobacco industry to keep or even enroll new segments of the population into nicotine addiction, and they also underline the lack of evidence regarding the long-term safety of these new devices. Although the latter argument can be appropriate for drugs, it does not seem to be relevant regarding alternatives to cigarettes when used by smokers, because no other product than cigarettes kills half of its 
users. The relative risk for lung cancer exceeds 20 in daily smokers compared with non-smokers. The high prevalence of such a risky behavior explains why lung cancer kills more people than any other cancer. After one decade of rapid raise of ecigs and a growing number of published studies, there is still very little evidence of any risks associated with their usage (Hajek et al. 2014), suggesting that if any risk of ecigs is ever discovered, it should not be as frequent as lung cancer, nor with such strength of association. Even the strongest opponents to ecigs do not foresee that the risk of consumption of smokeless tobacco or ecigs, when used by smokers, may be comparable to the risk of cigarettes. The problem would therefore be the risk of ecigs use by young non-smokers, if it lead them to nicotine addiction and to subsequent smoking. Although theoretically possible, this risk has not yet been supported by any study (Hajek et al. 2014). In a publication that received much media coverage (Corey et al. 2013), the US Centers for Disease Control and Prevention pretended that ecigs use by adolescents led to smoking, but in fact, this study was based on cross-sectional data that cannot be used to derive causal inferences. In addition, there is no evidence of such an issue with snus in Sweden, or with nicotine medications, which have been available without prescription for years. It seems that tobacco is needed to initiate nicotine addiction.

Another background element which may explain why many public health scientists and tobaccologists are opposed to ecigs has an historical origin. When the tobacco industry launched "light cigarettes", many doctors and scientists advocated them as less harmful than regular cigarettes, when in fact they are as or even more dangerous. Cynically, the tobacco industry was well aware from the beginning of the absence of harm reduction from light cigarettes. It is noteworthy that the tobacco industry was not at the origin of the production of ecigs. They stepped in this market in 2012 only, when Lorillard purchased Blu ecigs. Today, the tobacco industry intends to lead this market and, using its influence on regulators, to eliminate competitors. Some analysts even foresee important losses for this industry if they keep selling cigarettes only, a reason why this industry is now investing massively in ecigs and in other new products (e.g., heated tobacco products). Several countries recently implemented regulations aimed at controlling ecigs use and at improving their quality. However, these regulations may have the undesired effect of fostering large companies, particularly tobacco and pharmaceutical companies, instead of small manufacturers, because only large companies can survive in a strictly regulated environment. This would stifle innovation and competition, and give the tobacco industry a leading position in this new market.

Finally, let's underline the role of citizens and activist groups. Their influence was critical when the European
Parliament gave up regulating ecigs as medicines in 2013. It reminds us of the role activists played in the early times of AIDS, when the medical and scientific communities were not yet mobilized against this emerging pandemic, the pharmaceutical industry was not yet committed to looking for drugs, and politicians were under the influence of various lobbies, in particular conservative and religious groups. Ecigs activists are defending their right to use alternatives to cigarettes and do not intend to let other people, including public health experts, dictate their lifestyle. They know that they are escaping from the fatal threat of smoking through much less harmful alternatives, and some of them are willing to fight hard to make their "vaping" products accessible. Implementing effective and acceptable policies implies to better understand the role of non-governmental organizations and activists, and to involve them in the elaboration of these policies, as suggested by the WHO Ottawa Charter almost 30 years ago (Hancock 2013).

The consultation procedure for the new Swiss Tobacco Law ends on September 12, 2014. This law will regulate electronic cigarettes and all citizens can participate in this procedure (Confédération suisse 2014). The stakes are high, and it is critical to base regulations on the scientific evidence and a wide consultation of all stakeholders.

Conflict of interest AF has no conflict of interest with tobacco companies nor with manufacturers of e-cigarettes. JFE was reimbursed by a manufacturer of e-cigarettes for traveling to London and to China; he was not paid for these talks.

\section{References}

ASH Action on Smoking and Health (2014) Smoking statistics. Facts at a glance. Action on Smoking and Health, UK. http://www.ash. org.uk

Confédération suisse (2014) Loi fédérale sur les produits du tabac: Consultation. http://www.adminch/ch/f/gg/pc/pendenthtml

Corey C, Wang B, Johnson SE, Apelberg B, Husten C, King B (2013) Electronic cigarette use among middle and high school students-united stated 2001-2012. Morb Mortal Wkly Rep 62:729-730

Hajek P, Etter JF, Benowitz N, Eissenberg T, McRobbie H (2014) Electronic cigarettes: review of use, content, safety, effects on smokers and potential for harm and benefits. Addiction. doi:10. 1111/add.12659

Hancock T (2013) The Ottawa charter at 25. Can J Public Health 102:404-406

Norberg M, Malmberg G, Ng N, Brostrom G (2011) Who is using snus? Time trends, socioeconomic and geographic characteristics of snus users in the ageing Swedish population. BMC Public Health 11:929

Shibuya K, Ciecierski C, Guindon E, Bettcher DW, Evans DB, Murray CJ (2003) Who framework convention on tobacco control: development of an evidence based global public health treaty. BMJ 327:154-157

WHO (2104) Tobacco key facts. World Health Organization Fact sheet $N^{\circ} 339$ 2014. http://www.who.int/mediacentre/factsheets/ fs339/en/ 